\title{
La IV Consulta Post-Helsinki de la Conferencia de Iglesias Europeas (CEC)
}

POR MATIAS GARCIA

Del 29 de mayo al 4 de junio de 1980 se celebró en El Escorial la IV Con sulta Post-Helsinki, organizada por la Conference of European Churches (CEC), una de las organizaciones ecuménicas regionales de las lglesias federadas en el Consejo Mundial de la Iglesias (CWC). El lema de esta reunión ha sido el siguiente: "El desarrollo de la confianza en el ámbito de los estados firmantes del Acta de Helsinki. Tareas para las iglesias." La Iglesia Católica no es miembro de la $\mathrm{CEC}$, pero mantiene una estrecha colaboración con ella a través del Consilium Conferentiarum Episcopalium Europae (CCEE) y estuvo oficialmente representada por Alfonso Alvarez Bolado S.l., vicepresidente de la Comisión "Justitia et Pax" en España y delegado de la CCEE para esta conferencia.

La similitud de propósitos entre lo pretendido en esa Consulta y los objem tivos de este número monográfico, la parecida metodología empleada en ella en relación con la que es habitual en las reflexiones de Fomento Social fuicio eclesial y cristiano sobre temas "profanos" pero de amplia repercusión humana, en estrecho diálogo con expertos e ínteresados de diversas tendencias) $y$, sobre todo, el interés objetivo de las diversas contribuciones de la reunión de El Escorial, nos han movido a proporcionar a nuestros lectores esta reseña de la Consulta, en la que, aunque sea de modo esquemático, procuramos reflejar las aportaciones y sugerencias más importantes para nuestro común propósito (1).

\section{ALOCUCION INTRODUCTORIA}

Se inició la consulta con la Alocución Introductoria del doctor GLENN GARFIELD WILLAMS, Secretario General de la Conferencia de Iglesias Europeas,

(1) Para su elaboración hemos contado con toda la documentación de la Consulta, puesta amablemente a nuestra disposición por Alvarez Bolado. El nos ha autorizado también a utilizar, en la forma que estimásemos conveniente, el informe personal redactado por él como delegado de la CCEE en la misma Consulta, así como las crónicas que con perecido esquema ha preparado para las revistas Iglesia Viva y Estudios Eclesiásticos y que aparecerán en los próxị" mos números de las mismas. Nuestra colaboración es básicamente un extracto de dicho informe, ampliado en algunos puntos con ayuda de la documentación original. Otros puntos están en cambio tratados con más detalle en las dos revistas citadas. A ella y a las mismas actas de la Consulta, una vez que se publiquen, nos remitimos. 
destinada a encuadrar la discusion, definir el proceso de la consulta y sugerir estas tres propuestas previas, que serian retomadas en diversos momentos de elia:

1.* La eficacia de la CSCE no puede basarse en enouentros aislados y puntuales como los de Helsinki, Belgrado o Madrid. Hay que dotarla de una es. tructura de continuidad (al menos de un secrevariado permanente), que per. mila a la opinión pública concretar: "Aquí está Helsinki aquí está la CSCE."

2.5 Ello supuesto, en el proceso continuo que ligaria las proximas reuniones de la CSCE, debería participar un nuevo sistema de Organizaciones No Gubernamentales (ONG), con un estatuto análogo al que tienen en la ONU.

3. Habria que socializar el potencial de Helsinki con una mayor participación de la opinión pública en el proceso (v. gr. por medio de una revista ad hoc o de "Asociaciones Helsinki", parecidas a las de la ONU).

\section{INTERVENCIONES DE $10 S$ EXPERTOS}

Estas intervenciones de los expertos, a las que se dedicó el 30 y 31 de mayo y que estaban destinadas a iluminar técnicamente el estado de la cuestión, se iniciaron con una mesa redonda y se continuaron con las dos ponencias fundamentales de las que trataremos más adelante.

a) Mesa redonda entre expertos. Participaron básicamente en ella, con tres importantes contribuciones, Mrs. HELVI SIPILA (del Secretariado de la ONU en Viena), el profesor von WEIZSÄCKER (del Marx Planck Institut) y el profesor KOUTSENKOV (de la Academia de Ciencias de la URSS).

Mrs, SIPLL̈, coincidiendo con las propuestas $2 .^{a}$ y $3 .^{*}$ de la Alocución Introductorla, subrayó sobre todo la necesidad de un fomento de la participación popular, no gubernamental, en los procesos de distensión y cooperación. Puso también de relieve que uno de los factores que más perturban el clima de confianza entre los Estados es el creciente desfase entre paises desarroliados y en vías de desarrollo. Se ha conseguido muy poco en la construcción de un Nuevo Orden Económico Internacional y, a pesar de los esfuerzos de las N.U., la carrera de armamentos continúa. Ante ambos hechos, es preciso que el pueblo en su conjunto tome conciencia del problema y se oponga eficazmente a esa carrera, superando la falsa opinión de que ella contribuye a su propia seguridad. Pero, para ello, el pueblo debe ser adecuadamente informado sobre las posibilidades de otras alternativas. En ello tienen una especial responsabilidad las Iglesias.

El profesor WEIZSACKER afirmó que un lúcido y cristiano "amor a los enemigos" comienza interesándose por la imagen que el adversario tiene de nos" otros mismos, imagen que alimenta sú temor y odio hacia nosotros. A partir de este esfuerzo de comprensión, analizó la dialéctica de ambos bloques, con. secuencia de su respectivo temor y angustia. Los dos sistemas de alianzas se entienden sinceramente como defensivos. Pero la carrera de armamentos, que así queda justificada, alimenta también la esperanza de ganar un dia la batalla del sistema social que cada uno de los bloques representa.

Los uttimos meses nos han mostrado en tres gravisimos acontecimientos a sonde puede conducirnos esa dialéctica. 
- Los sucesos del iran muestran al pueblo americano "lo odiado e impotente que es hoy en extensos ámbitos del mundon. Su allanza con gobiemos tiránicos fjustificada por la diplomacia occidental como realista medida estabilizadora, en su estrategia defensiva mundial contra el comunismo militante] hace nacer la sospecha de insinceridad en su pretendida defensa de los valores de la democracia.

- La decisión de rearme por parte de la OTAN muestra en cambio á la Unión Soviética el temor que produce en la alianza occidental el siempre creciente rearme soviético. Pero Occidente no cae suficientemente en la cuenta de que la Unión Soviética se siente como estrangulada por la superioridad tecnológica y económica de Occidente y por la presencia mundial de las alianzas americanas. A su vez, la Unión Soviética es incapaz de percibir que ese anillo de alianzas no es sino "la reacción defensiva de todos sus vecinos que se sienten amenazados por su poder militar y por su doctrina de la legitimidad de todos los movimientos revolucionarios que a ella se aliann.

- Finalmente, la invasión soviética de Afganistán ha supuesto una conmoción irreparable de las relaciones internacionales, tanto más grave, cuanto que ella representa una repetición de parecidas intervenciones en ef pasado: "las mayorías no comunistas en los pueblos de todas las tierras se preguntan hoy cuándo le tocará la suerte a su propio país».

En orden a solucionar esta situación, Weizsäcker se limitó a estas dos observaciones. La primera en relación a la evitación del rearmex a pesar de las imperfecciones del acuerdo Salt II, su firma representa una fase imprescindible; inmediatamente después habría que exigir que se retiren de ambas partes de Europa los misiles de rango medio, que amenazan su supervivencia. La segunda se refiere al respeto a la soberanía de todas las naciones: habria que pedir a la Unión Soviética una neta renuncia a la ocupación de Estados soberanos. Puesto que unos y otros han obrado así en el pasado, no se trata "de aumentar ahora con ocasión de Afganistán la lista de reproches mutuos. Se trata de la sobria prognosis de que la continuación de la política de inter. vención de cualquiera de las dos partes provoca inevitablemente intervenciones de la otra, y que este proceso sólo puede terminar con una tercera guerra mundial". Hay que dar una señal clara de que esa política de intervención no se continuará en Europa, ni en ninguna otra parte. Cómo ha de ser esa señal es ol objeto de las negociaciones políticas; pero las Iglesias pueden pedir que se dé.

El profesor KOUTSENKOV dedicó buena parte de su intervención a extractar la reciente declaración de los miembros del Pacto de Varsovia (14m 15 de mayo de 1980). Dljo además que la confianza no tiene dimensiones cuantitativas y enumeró muchos resultados positivos del Acta de Helsinki (sólo la Unión So. viêtica ha firmado más de 1.500 acuerdos de cooperación industrial con Europa Occidental). La crisis de Helsinki, surgida sobre todo en el área militar, la atribuyó "a los intereses egoístas de los grandes productores de armasn: bajo su presión, la OTAN adoptó la arriesgada decisión de situar en Europa los nuevos misiles americanos de alcance medio. Ello ha roto la paridad de fuerzas y ha intensificado en la opinión pública soviética el miedo que le produce una Alemania armada.

b) Ponencia de WOLF VON BAUDISSIN (General retirado del ęercito alemán y, actualmente, miembro del Instituto de Investigación para la paz y la Politica de Seguridad, en Hamburgol. 


\section{MATIAS GARCIA}

Esta fue seguramente la ponencia más densa, elaborada y realista de la Consulta, que en el debate fue calificada como de un "optimismo no-sentimental". He aqui sus principales ideas: A pesar de la agravada situación internacional, hay que reconocer la fructuosidad del proceso de Helsinki y la oportunidad que no debería desaprovecharse-de la conferencia de Madrid. No cree -en contraste con WEIZSACKER-en la probabilidad de una guerra; tampoco estina realista el pretender un desarme absoluto; según él, lo único operativo es el control conjunto y cooperativo del conflicto y de la carrera de armas

Sobre esta base adquieren todo su valor las siguientes reflexiones y reco mendaciones. La distensión no progresa debido a una insuficiente conciencia pública del conflicto y de su complejidad; es peligroso creer que él puede solucionarse con medidas simplistas y drásticas. Ese ubloqueo psicológico" sólo puede superarse "por una paciente educación que capacite para soportar y administrar los conflictos", lo cual exige un alto nivel de información en los ciudadanos en las siguientes cuestiones: sobre las concepciones contradictoras de la distensión; sobre la necesidad de seguridad por ambas partes; sobre las estrategias y políticas de seguridad (también contradictorias y con diversos motivos y fundamentos); sobre la problemática y el desarrollo del "control de armamentos"; sobre las expectativas y resultados de los encuentros y conferencias más importantes; sobre la necesidad-desde el punto de vista de la seguridad-de que las medidas militares para conservar la estabilidad estratégica se apoyen cada vez más en la interdependencia comercial. En todo ello tienen una gran tarea que cumplir las Iglesias.

Por otro lado, el proceso de desarrollo y modernización crea procesos cada vez más conflictivos en el hemisferio Sur, que repercuten directa o indirecta. mente en el Norte. El Norte tiene que cobrar conciencia de ello y buscar soluciones que no se hagan a costa del Sur; para lograrlo hay que superar prejui cios, ideologías y angustias hondamente asentados.

En ambas tareas tienen amplias posibilidades de acción eficaz las $O N G$, pero sobre todo las Iglesias, debido a su interna red de información (que les permite formarse una imagen de la situación relativamente adecuada), a sus contactos para verificar lo que se dice y sacar consecuencias (que pueden comunicarse a la opinión pública y a los que tienen poder de decisión), a su caracter apartidista (sobre todo scuando resisten a la tentación de constituir se en fuentes de competencia técnica excesivamente detalladan), a su capacidad de suplencia (cuando fracasan los canales diplomáticos) y, finalmente, a su posibilidad de poner en cuestión (a partir de su imagen del hombre) los clichés, las imágenes del enemigo y las abstracciones de los conceptos ideológicos.

c) Ponencia de MIHALY SIMAl (Economista húngaro de la Federación Mundial de Asociaciones de las N.U.). Si la ponencia de von BAUDISSIN iluminó el tema desde la perspectiva militar, ésta la iluminó desde el ángulo económico. Ella además está claramente concebida desde una postura prosoviética.

Coincidiendo con von BAUDISSIN, puso de relieve que el tercer mundo será el arrea de las mayores transformaciones sociopolíticas en las próximas décadas y que ues vital para toda la humanidad que las tensiones y conflictos radicados en este proceso no entren en las áreas centrales de las relaciones internaclonales, que son todavía y permanecerán en el futuro previsible relaciones entre los países de la OTAN y el Pacto de Varsovia y entre USA y la URSS*. 
En el campo del intercambio-comercial, cientifico y culzural-señaló "ciertas diferencias entre los paises europeos occidentales y el comportamiento de USAn: mientras que en los primeros las relaciones económicas y comerciales con la Europa Oriental se expandieron rápidamente en el clima de distensión, en USA la "enmienda Jackson-Vanik" impidió que se diera a la URSS el trato de cliente "más favorecido".

En cuanto a los acontecimientos que han perturbado la distensión, su punto de vista fue el siguiente. En primer lugar lamentó "la amarga campaña de propaganda contra ciertos países socialistas, acusándoles de violación de los derechos humanos"; según él, también esos paŕses reconocen "la importancia de los derechos humanos..., aunque daban prioridad a los derechos económicos, sociales y culturales y consideraban estos derechos como condiciones indispensables que establecian la base realista para la defensa de la dignidad humana y para los derechos civiles y políticos". Lamentó en segundo lugar el que USA y la OTAN hayan intentado cambiar sin necesidad estratégica el equilibrio militar y tratado de "restaurar la superioridad militar"; a este pro pósito se refirió en los siguientes términos a las consecuencias de la carrera de armamentos: "al final de los años 1970 el presupuesto global militar se acercaba a los 450 billones por año. Que equivale al ingreso anual de la mitad más pobre de la población de nuestro planeta". Afirmó en tercer lugar que son esos hechos y procesos, y no la intervención en Afganistán, los que han deteriorado la distensión y la cooperación: "No fue la asistencia soviética a las fuerzas progresivas en Afganistán las que iniciaron ese proceso... Era evidente entonces y es claro ahora que la Unión Soviética sólo a disgusto se decidió a aytudar en orden a evitar el surgimiento de un régimen de tipo chíleno, la masacre de decenas de miles y el retroceso de Afganistán a la Edad Media."

Es evidente que en este punto sus opiniones no encontraron apoyo en los expertos de países no socialistas. En cambio sí existió unanimidad en apoyar su insistencia "en orden a generar la voluntad política y el apoyo público necesario para el desarme y otros objetivos prioritarios, como el de la seguridad económica, que es "una cuestión vital para los 114-120 países en vías de desarrollo". Ello implica un cambio en las relaciones económicas internacionales y el establecimiento de un nuevo orden económico internacional. Para superar los retos de las próximas dos décadas (en ellas, p. ej., habrá que proporcionar trabajo a 500 millones de jóvenes) es necesario que se intensifique la cooperación internacional, que además operará como instrumento de distensión. Para ello no basta la cooperación Este-Oeste; ambos deben además colaborar en el esfuerzo "por una descolonización económica y un nuevo sistema de relaciones económicas internacionales".

\section{MESA REDONDA PARA ABORDAR EL TEMA DE LAS TAREAS DE LAS IGLESIAS}

En la tarde del sábado día 31 de mayo comenzaron las reuniones de los Grupos de Trabajo, que se continuarian-tras el descanso del domingo-en la tarde del lunes 2 y la mañana del martes 3. La mañana del lunes 2 se dedicó - sobre la base de las ponencias y discusiones entre expertos, y en orden a lluminar el trabajo ya iniciado de los grupos-a una mesa redonda, en la que intervinieron con sendas miniponencias el profesor de ética HANS RUH (suizo y evangélico), el obispo HURST GIENKE (representante de la Iglesia evangélica de (a DDR) y Mr. CLUDE GRUSSON (de la federación protestante francesa), y en la que también participaron Mrs. ALICE WIMER (del NCC de USA) y Mr. MUPRAY THOMPSON (del CCC de Canadá). Resumimos las líneas principales. 


\section{MATIAS GARCIA}

a) Miniponencia del profesor RUH. Toda ella está basada en el análisis de la confianza, como factor condicionante de la seguridad en la comunicación humana. La confianza y la misma cultura de la confianza está actualmente degradada. No se puede recomponer ni con palabras ni con meros postulados, sino únicamente con una praxis que no tenga necesariamente como presupuesto inicial la recipfocidad. Insinuaba así que la reciprocidad es más bien efecto de esa praxis que, en cierta manera, comienza siendo unilateral.

El axioma sobre el que dicha praxis puede fundarse lo cree encontrar en lo que $\mathrm{H}$. AFHERDT llama imperativo categórico del desarme: "Cada bloque militar de tal forma debe desarrollar, hacer transparente y practicar un concepto estratétigo, que el adversario pueda reconocer que, al construir mi propio proyecto de seguridad, estoy teniendo también en cuenta la seguridad del adversario.. Es evidente la similitud de esta concepción con las reflexiones ético-politicas de Weizsäcker y las propuestas de politica militar de von Baudissin.

Como también decía Weizsäcker, la forma estratégica de realización de ese imperativo es misión de los políticos, pero es tarea propia de las Iglesias promover el desarrollo de tales estrategias en el propio país. Esa tarea de las Iglesias en la promoción de proyectos estratégicos que restauren la cultura de la confianza la concretó Ruh en estas ocho exigencias.

1. Lo interesante no es lo que una Iglesia recomienda hacer a otras, sino lo que cada iglesia hace en su propio territorio en favor de tal forma de com portamiento o para hacerla posible.

2." En su propio territorio las Iglesias tienen el deber de impulsar a sus gobernantes a que den pasos en el sentido indicado, sin esperar a que otros los den.

3." Ese sentido consiste en no maximizar el propio poder, sino incluir, en el proyecto de la propia seguridad, la atención a las condiciones de posibilidad de la del otro.

4.a En su ámbito cada Iglesia toma sobre sí la responsabilidad de dar los primeros pasos en esa dirección. Las iglesias no deben decir nada que no puedan hacer; pero deben hacer lo que dicen.

5. En el propio territorio la lglesia colabora a evitar a largo alcance las posibles causas de violencia y guerra, sobre todo en relación con el subdesarrollo.

6. La lglesia ofrece espacios a proyectos de seguridad alternativos. Ello significa que...

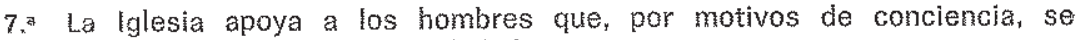
oponen a los conceptos de seguridad dominantes.

8. La comunidad internacional de las Iglesias se entiende como federación, cuya dinámica vive de que cada Iglesia, en su caso y en su territorio, se comporta y hace camino en la dirección indicada.

b) Las otras miniponencias y contribuclones. La miniponencia del obispo GIENKE consistió en una simple enumeración de to que en este sentido han hecho las lglesias en la zona oriental en estos cuatro campos: hacia la propla 
comunidad y la opinión pública de las mismas iglesias, conversaciones bilaterales ecuménicas entre las Iglesias de USA y Canada por una parte y la iglesia Evangélica de la DDR por otra, contactos con los propios gobiernos $y$. finalmente, con grupos no cristianos pero de análoga finalidad.

En su miniponencia, M. GRUSSON insistió en la necesidad de socializar y hacer transparentes los procesos cientificos y tecrológicos que estan en el fondo de la dificultad.

En cuanto a los representantes de USA y Canadá, que sólo tras los sucesos de Irán y Afganistán se decidieron a participar en la Consulta, Mrs. ALICE WMER indicó que sus Iglesias estaban ahora más polarizadas hacia el Tercer Mundo y al Próximo Oriente, aunque también mantenían contactos directos con las Iglesias de Rusia y Alemania Oriental. Mr. MURRAY THOMPSON insistió en la necesidad de movilizar recursos, pero sobre todo de movilizar el interés público en todas estas cuestiones.

\section{GRUPOS DE TRABAJO}

Ya hemos indicado que a ellos se dedicó la mitad de los tres útimos días de trabajo. De ellos debían partir las propuestas que serían sometidas a votación la última tarde.

Al llegar a este punto y antes de hacer un resumen del contenido de dichas propuestas, conviene hacer una reflexión sobre la merodología seguida en el coloquio. En ella tiene mucha importancia la misma composición del grupo. A pesar de tratarse de una Consulta de la Conferencia Europea de las Iglesias, sólo la mitad aproximada de sus componentes eran representantes de lglesias (14 de Europa Occidental, 10 de la Oriental y otros 5 de diversas procedencias). El resto estaba formado por representantes de diversos institutos de análisis sobre la paz o similares, de Organizaciones No Gubernmentales reclesiales o profanas) y de instituciones de las N.U. con un adecuado equilibrio entre los diversos bloques políticos e ideológicos. Se pretendía en efecto que, en ese ambiente de asesoramiento técníco suficientemente equilibrado ideológicamente, los representantes de las Iglesias pudiesen decir su palabra específica, sin por ello instrumentalizar a los expertos y a los participantes de otras ONG, ya que ellos-junto con los representantes de Iglesias-participarian en las votaclones finales. En ello no había especial dificultad, ya que las recomendaciones votadas no tienen el carácter de decisiones de las Iglesias, ni de la CEC, sino que son recomendaciones de la Consulta a las Iglesias-miembros de la CEC o a sus organismos ejecutivo y consultivo.

En cuanto al papel de los expertos, ellos mismos reconocieron que dificilmente se ponen de acuerdo en relación con las últimas informaciones e interpretaciones, ya que dependen en ello de su alineación en una u otra alianza. Von Baudissin indicaba que a partir de esa conciencia de contradicción es cómo las Iglesias tienen que cumplir su papel de mediación, de pedagogía del conflicto y de estrategia ético-política para su superación. Lo cual no significa que las lglesias puedan prescindir de esos juicios de los expertos: sólo escum chándolos pueden localizar las posibles convergencias y detectar las diferencias insalvables, que, verdaderas o falsas, determinan realmente a sectores muy importantes de la opinión pública y, por tanto, configuran el real estado de la cuestión en el conflicto. 


\section{RECONENDACIONES A LAS IGLESIAS}

La CEC no ha proporcionado todavia un texto completo y de alguna forma "oficial" de todas las propuestas aprobadas en la última reunión plenaria de la Consulta. Disponemos ciertamente de las propuestas de recomendación elaboradas por los tres grupos de trabajo, muchas de las cuales son coincidentes en su contenido, aunque tengan diversa redacción. Sabemos también qué acogida tuvieron en la Plenaria. Contamos además con el Comunicado Final, que recoge algunas de las recomendaciones aprobadas. Con estos elementos nosotros hemos seleccionado y ordenado las siguientes recomendaciones que nos parecen más significativas.

\section{Recomendaciones que recogen las propuestas del Secretario General}

1. Que las Iglesiasmiembros de la CEC pidan a sus gobienos respectivos:

a) Que convoquen reuniones especiales con los representantes de las Iglesias, Organizaciones No Gubernamentales (ONG) e Institutos para la búsqueda de la paz, a fin de discutir intereses y propuestas comunes, relativas a la reunión de Madrid.

b) Oue estudien la posibilidad de proporcionar una estructura permanente, que se ocupe de las cuestiones que entran dentro del ámbito de validez del Acta Final de Helsinki. Dicha estructura podría tomar la forma de un pequeño secretariado permanente, encargado de preparar reuniones de seguimiento de la CSCE y de fomentar el intercambio de información y opinión acerca de ella, incluyendo una publicación regular en las lenguas más difundidas en el área de Helsinki.

2." Oue las Iglesias-miembros de la CEC:

a) Den su apoyo a la formación de "Asociaciones de Helsinki" sobre el modelo de las asociaciones de las N.U., para promover el trabajo de la CSCE entre el público en general.

Nota. ista propuesta fue aprobada con muy escaso margen y no consta en el comunicado final. La razón es que muchos pensaron que los gobiemos socialistas no aprobarian tales asociaciones, que se convertirian en instrumentos de lucha de la oposición.

b) Apoyen y fomenten el programa de derechos humanos de las iglesias para el cumplimiento del Acta Final de Helsinki, que se lleva adelante de forma conjunta por el Congreso Canadiense de las Iglesias, la Conferencia de Iglesias europeas y el Consejo Nacional de Iglesias de Cristo en USA.

\section{Recomendaciones relativas al desarme}

\section{y al cumplimiento de los acuerdos de Helsinki}

3. Que la CEC ruegue a sus fglesias-miembros que evalúen o re-evalúen su postura en cuanto a la posesión y uso de armas nucleares para contribuir a una politica de seguridad y defensa, que no sigue todavía dependiendo de la reciproca disuasión nuclear.

4. ${ }^{*}$ Pogamos a las Iglesias a través de la CEC:

a) Otie, por lo que atañe al concepto de "Seguridad Nacional», urjan a los gobiemos a considerar una moratoria respecto al rearme. (p. ej., en relación 
a los cohetes de medio alcance de ambas alianzas); a dar los pasos adecuados para emprender negociaciones dentro y entre ambas alianzas, a fin de conseguir una nueva base para el control y reducción de armamento; a tomar con. ciencia de la importancia de la ratificación e implementación de SALT II; a aprobar la prohibición completa de pruebas nucleares y de armas quimicas; a continuar con más empeño las actuales negociaciones sobre MBFR (Mutual Balanced Force Reductions), y comenzar en seguida con las negociaciones so. bre SALT III.

b) Que insten a los gobiernos a hacer plenamente efectiva el Acta Final de Helsinki, incluso en acuellos puntos que, en las tres primeras "cestas", no han sido todavia cumplidos.

c) Que urjan a los gobiernos a atenerse estrictamnte a los 10 Principios, tal como ellos se expresan en detalle en el Acta Final, así como a buscar urgentemente soluciones políticas en todos los campos de la actual crisis.

5.a Que se celebre una consulta especial de la CEC sobre educación para la paz.

\section{Recomendaciones més dîrectamente relacionadas}

con la próxima conferencia de Madrid (véase también 1.a, a)

6. Que las Iglesias apelen a los gobiernos para que, en el espiritu de Helsinki, den espontáneamente pruebas que muestren con claxidad, ya antes de la Conferencia de Madrid en noviembre de 1980, que están dispuestos a proceder conforme a lo tratado; y que les recomienden con instancia que se esfuercen, en el mismo comienzo de la Conferencia de Madrid, a hacer propues" tas positivas o a ponerse de acuerdo en algunos puntos. Ello ayudaría a crear una atmósfera de negociación, en la cual se podrían tratar también cuestiones más dificles con más perspectivas de éxito.

7.2 Que durante y después de la CSCE de Madrid en 1980 se forme un grupo de contacto de "Comunicación e Información" sin estatuto oficial. Se ruega a la CEC proporcionar ayuda para la coordinación.

8. Que la presidencia de la CEC hagla una propuesta concreta al Secretariado del grupo de seguimiento de la CSCE en Madrid para la consecución de un estatuto consultivo. 